\title{
CELIA GÁMEZ: UNA VERSÁTIL DIVA ESCÉNICA
}

\author{
CELIA GÁMEZ : A VERSATILE SCENIC DIVA
}

María Teresa Arias Bautista Agrupación Ateneísta de Estudios sobre las Mujeres "Clara Campoamor"

\section{RESUMEN:}

Celia Gámez fue una diva escénica durante muchísimos años porque supo nadar en todas las aguas gracias a una versatilidad única. De sus espectáculos desaparecieron, tras la Guerra Civil, la ordinariez y la sicalipsis, y logró la aquiescencia de muchas mujeres y de la censura franquista, pero siguieron reflejando la doble moral imperante, y un ideario que cercenó las libertades de todos y las esperanzas de muchas mujeres.

\section{Palabras claves:}

Celia Gámez, revista teatral, mujer.

\section{Abstract:}

Celia Gámez was a stage diva for many years because she knew how to swim in all kind of waters thanks to a unique versatility. After the Civil War, vulgarity and suggestiveness disappeared of their shows, and she obtained the acquiescence of many women and Francoist censorship, but continued reflecting the prevailing double standards, and an ideology that curtailed freedoms of all and hopes of a lot of women.

\section{KEY WORD:}

Celia Gámez, theater magazine, woman. 


\section{INTRODUCCIÓN}

Hablar de Celia Gámez requiere, necesariamente, hablar de un género teatral que evolucionó a lo largo de su trayectoria histórica al compás no solo de los gustos de los espectadores, sino de las intensas transformaciones sociales y políticas acaecidas desde finales del siglo XIX, en que aparece, hasta el último cuarto del siglo XX. De ahí que parezca imprescindible, aunque sea muy brevemente, poner de relieve la evolución de la escena sobre la que se iban a desarrollar las diferentes representaciones.

\subsection{El marco temporal de un espectáculo}

La revista, olvidada y denostada durante mucho tiempo ${ }^{1}$, ha recibido recientemente la atención de varios investigadores ${ }^{2}$ que han comenzado a cubrir un espacio de tiempo considerable dentro del análisis de la escena teatral. No obstante, falta mucho por hacer $\mathrm{y}$, especialmente, desde el punto de vista de los estudios de género, puesto que a través de los libretos de las innumerables obras que aún se conservan pueden hallarse múltiples referencias a los cambios sociales, la estructura ideológica y la política social con respecto a las mujeres, así como la óptica con que se percibía el mundo femenino, sus avances, aspiraciones y retrocesos.

La definición que de la revista hace la Real Academia de la Lengua atiende a la forma en que la entendemos hoy en día, pero esta dista mucho de lo que fue en sus inicios y ni siquiera se ajusta a la de hace unos pocos años. Efectivamente, hoy podemos leer que se trata de un "Espectáculo teatral de variedades, en el que alternan números dialogados y musicales de carácter festivo". No obstante, hace unos pocos años la definición era otra: “Espectáculo teatral de carácter frívolo, en el que se alternan números dialogados y musicales". Ello nos remite a las reformulaciones que se van realizando al paso del estudio de su materia y de la eliminación de nuestro lenguaje de contenidos esencialmente moralistas.

Pero, como acabo de indicar, la definición de la revista de hace pocos años, o la actual, nada tienen que ver con sus inicios en el siglo XIX, cuando únicamente pretendía poner en escena los acontecimientos más significativos del año ${ }^{3}$ ni con su 1 El desprestigio en que quedó arrumbado este género ha sido tal que muchas de las obras han
desaparecido y se sabe de su existencia porque en algún medio se ha conservado el nombre. A veces ni siquiera eso, pues han quedado "perdidas en la nebulosa de los tiempos" (Femenía 1997: 5).

2 Especial mención merecen las obras que han ido surgiendo de la pluma de Juan José Montijano Ruiz a partir de su tesis doctoral, presentada en la Universidad de Granada, en 2009, bajo el título "Historia del teatro olvidado: la revista (1864-2009).

3 Todos los autores coinciden en cifrar el arranque del subgénero en 1864, cuando José María Gutiérrez de Alba tiene la gran idea, en un largo paseo de Madrid a Carabanchel, de "glosar" los acontecimientos del año de forma evolución a principios de los años XX; mucho menos, de su efervescencia durante la etapa republicana y su redefinición y consolidación durante la dictadura franquista ${ }^{4}$.

A lo largo de todo este período de tiempo se irá configurando su estructura definitiva merced a los gustos de los espectadores, en principio esencialmente masculinos, la situación política -más o menos transigente con el lenguaje, la exhibición del cuerpo femenino y la procacidad de ambos-, así como con las innumerables fuentes de las que beberá e irá incorporando elementos:

\section{La revista es una modalidad de género chico que ha tenido una larga descendencia procedente de las "revistas del año" y de los Bufos, pero incluye rasgos del sainete. De las revistas del año toma la yuxtaposición de escenas y la sátira política de actualidad; de los Bufos, la espectacularidad y el atractivo erótico de las bailarinas; del sainete, sobre todo, la materia musical de la misma: ritmos de los bailes de moda y folclore urbano y regional (Barce, 1996-97: 119).}

Desde luego, en lo que sí parece que coincidirá la revista en todos los períodos fue en tratarse de "un espectáculo que se ofrece a la vista del público para divertirlo, escandalizarlo, distraerlo y emocionarlo" (Montijano, 2009: 58).

\subsection{Las mujeres y la revista}

Como se acaba de indicar la revista fue dirigida hacia y consumida por un público esencialmente masculino durante un período de tiempo considerable, que hizo de la mujer y del cuerpo femenino parte esencial del espectáculo ${ }^{5}$. Ya en la que se considera el origen de este género teatral, lo más atrayente para los espectadores fueron los personajes femeninos que encarnaban la Moda, la Danza, la Lotería, el Lujo...

retrospectiva, pasando "revista" a los mismos. La obra, titulada 1864 y 1865, fue musicada por e maestro Cristóbal Oudrid y estrenada con gran éxito en el Teatro Circo el 30 de enero de 1865 Permaneció varios meses en cartel, recorrió toda España y de la misma se hicieron nueve ediciones" (Sánchez, 2005: 22).

4 Montijano hace una clasificación de la revista surgida a partir de 1910, con la incorporación de los más variados elementos y en función de la prevalencia de los mismos (Montijano, 2009: 88-89).

5 “La máxima de la revista giró siempre en torno a dos palabras clave: música y mujeres” (Montijano, 2009: 165). Los argumentos, vanos e intranscendentes, servían para orquestar lo anterior, entre enredos desenfadados que buscaban la evasión y la hilaridad de los espectadores. Montijano ha realizado una clasificación de las revistas en función de que las mujeres hagan aparición expresa en el título, o haya referencia indirecta a ellas; también los que hablan de su estado social y civil su posición social, sus características, erotismo, emancipación, atributos o rasgos femeninos, incapacidad de desempeñar algunos oficios, los que las señalan como objeto de admiración, hacen referencia a su origen y procedencia, a expresiones típicas femeninas, los que nombran a una mujer o personaje determinado, o se refieren a personajes femeninos legendarios ya sean reales o ficticios, los que implican un descarado machismo, o bien acciones de hombres que tienen como principa
objetivo la mujer (Montijano, 2009:

169-172) 
Pero, no bastaba con la mera exhibición de ese cuerpo para recreo visual de los asistentes, sino que aún se alcanzó un grado más elevado de connivencia entre los creadores y los espectadores en la que se considera el antecedente de la revista frívola: El joven Telémaco. En ella triunfó la palabra suripanta, que carente de significado hasta el momento, pasó a denominar a las coristas y por extensión a la "mujer ruin, moralmente despreciable", según pone de manifiesto el diccionario de la Real Academia. Una dualidad léxica nacida de la doble moral que incitaba a los varones al disfrute de un cuerpo femenino, inmediatamente denostado, porque esa tipología de mujer se alejaba del perfecto ángel del hogar, paradigma extensamente pregonado, apartado de todo atisbo de sexualidad, en tanto en cuanto había de ser únicamente reproductor del varón con el que conviviera.

A partir de entonces y en un crescendo que culminó en el período de la Segunda República, la poca ropa de las mujeres participantes y su gestualidad, ellenguaje de doble sentido que aparece incluso en los títulos, las referencias sexuales veladas o explícitas de los textos, chistes y canciones, todo ello rayano en ocasiones en la chabacanería y el mal gusto ${ }^{7}$, invitarán a un público masculino completamente entregado a asistir a estos espectáculos que, después, serán motivo de extenso comentario en las conversaciones.

Es en este momento histórico republicano en el que las mujeres tienen mayor oportunidad de reivindicar sus aspiraciones tanto tiempo enunciadas y aplazadas. Un tiempo en que cada vez más mujeres acceden de forma visible a la universidad, al ejercicio de profesiones antes inviables, a ocupar espacios en tribunas culturales, jurídicas, políticas, en los medios, etc. Curiosamente, también es cuando otras mujeres exponen su cuerpo a la mirada, como si esa exhibición fuese algo deseado por ellas',

6 Hace furor al igual que el término suripanta, otro vocablo: sicalipsis, que la Real Academia traduce como malicia sexual, picardía erótica.

7 "Con la entrada del nuevo siglo la revista va a sufrir una serie de cambios que se irán acentuando con el correr de los años.. se va a tornar en una descarada ordinariez que va a alcanzar su punto culminante alrededor de los años treinta... Con el aumento de la "sal gorda" en los libretos, de form abusiva en algunos casos, la revista entra en un proceso degenerativo del buen gusto que llega a abusiva en algunos casos, la revista entra en un proceso degenerativo del buen gusto que llega a 1931... La subida del nivel de ordinariez determinó el alejamiento de cierto sector de espectadores que no gustaban de la grosería escénica y sobre todo de las damas..." (Femenía, 1997: 147-148).

8 Como no podía ser de otra manera, pues el teatro refleja los cambios sociales y políticos de cada momento, la revista se vio enseguida afectada por los que agitaron a la República, no solo en los títulos, sino también en los contenidos: "La revista fue el primer género teatral en asimilar más fácilmente los cambios políticos. Títulos todos ellos de 1931, como Las gatas republicanas, iViva la República!, o Alfonso XIII de Bom Bom... fueron buena prueba de ello... Durante este período la revista va a vivir momentos de auténtico paroxismo... la libre exhibición de desnudos en el escenario, las libertades otorgadas por los políticos en muchos ámbitos de la sociedad y de la cultura, van quedar reflejadas en escena con argumentos como el divorcio, la liberación de la mujer, el derecho a voto y la profesionalización de ésta..." (Montijano, 2009: 409).

9 "El hecho de que las vedettes lucieran más o menos ropa carecía de la menor importancia, toda vez que fue esta una de las caracteristicas de este espectáculo, y quiza uno de los mayores atractivos, pues el lucimiento físico de las bellas mujeres siempre atrajo la atención del público, sobre todo en en una aparente liberación de los prejuicios decimonónicos, tan exacerbados y discutidos ${ }^{10}$, hijos de la reacción ante las exigencias de cambio femeninas que tomaron nuevos derroteros con el sufragismo. Su desnudez se presenta pues como un acto de valentía, como un referente de cambio, de liberación, de libertad, más que como un capricho para dar mayor placer al público al que iba destinado .

Lo peor es que detrás de todo ello seguía manteniéndose ese prejuicio ancestral contra las mujeres que se atrevían a exponerse y que no solo era patrimonio masculino, sino que ocupaba la mente de muchas mujeres, gracias al acierto con que se ha reproducido y reinventado siglo tras siglo el patriarcado. Las vedettes, efectivamente, eran mujeres públicas, al igual que las que se sentaron por vez primera en la Cámara de diputados, pero con un significado absolutamente diferente. Era como una burla del destino hacia lo femenino que perpetuaba los esquemas mas deleznables en una etapa cantada como libertaria, igualitaria y con ansías de huir de los encasillamientos y los estereotipos.

Por supuesto, las pretensiones y aspiraciones de mejoras familiares, laborales, sociales y políticas de las mujeres van a aparecer en numerosísimos libretos, pero será para escarnecerlas y ridiculizarlas. Así se pone de manifiesto en títulos como una época en que la moda lo tapaba todo o casi todo, y priva a la mujer de disfrutar de la admiración del sexo contrario, insinuando, más que enseñando, las gracias con que la naturaleza la había distinguido". (Femenía, 1997: 147).

10 “A finales del siglo XIX la mujer se convirtió en un asunto candente y de máxima actualidad que atrajo la atención de un amplio elenco masculino, compuesto por moralistas, científicos, filósofos, intelectuales y artistas. Ella será objeto de los análisis más variados, y no se reflexionará solo sobre sus derechos y el papel que debía ocupar en la sociedad, sino que preocupará también su fisiología, su psicología y su inteligencia, así como sus facetas más oscuras, misteriosas y fatales... El teatro de la época no iba a sustraerse a esa tendencia... (Fernández, 2009: 108).

11 “ ... cinco muchachitas del Romea que han tenido el gusto auténticamente moderno de colgar el sostén en la percha de las prendas inútiles, porque son cinco nombres para la historia de la civilización española y porque son cinco nombres que mañana habrán de buscar los reporteros que aún no han nacido para empezar su información: la primera vez que las segundas tiples salieron con los senos desnudos" (Barreiro, 2007: 98-99). 
Congreso feminista ${ }^{12}$, El trust de las mujeres ${ }^{13}$ o en el chotis de Las diputadas ${ }^{14}$, perteneciente a la revista Las mimosas; o en Enseñanza Libre, revista que con su abrupto tango de El morrongo, resultaba el contrapunto de lo que fue la Institución Libre de Enseñanza para las mujeres.

El triunfo del nacional-catolicismo dará un vuelco radical a este tipo de espectáculos. En aquel ideario rancio y pacato se anegará el pensamiento de varias generaciones. Una trampa de la época, inconfundible e incomparable, puesto que en España y en su entorno ya se habían respirado otros aires y se seguían respirando.

Nuevamente, y con mayor fuerza si cabe, se impondrá con respecto a las mujeres el yugo violento de la supervisión y control masculinos, edulcorado con el discurso del halago, anestesiado con la necesidad de salvaguarda de su honor, respetabilidad e integridad física.

La dictadura impuso una abierta doble moral genérica más exacerbada que la existente en períodos anteriores. Los varones eran libres, aunque el discurso pregonara otra cosa, de ejercer su sexualidad a costa del innumerable grupo de mujeres sin recursos, ni posibilidad de trabajo digno, que tenían que dar de comer a sus familias y ejercían la prostitución en la clandestinidad o se convertían en las "queridas" de todo aquel que podía permitirse el lujo de hacerlo. Contaban con la connivencia de su entorno, muchas veces incluso con el más íntimo. En ocasiones, la bigamia encubierta de los poderosos - que no anulaba escarceos múltiples de otro tipo-, se contemplaba como símbolo de virilidad y estatus. Mientras, la recalcitrante ideología, especialmente dictada sobre las mujeres, se imponía de forma contumaz y represora, ley en mano, valiéndose del miedo y el rechazo público para redirigir conductas poco recomendables 12 “ Orden, señoras, orden! $; Q u e$ esto va pareciendo una reunión de hombres!...Recuerde la oradora bello no hay manera de entenderse a los cinco minutos... Se trata de un hombre, que es el punto donde os habéis alborotado, que reconociendo nuestras aptitudes para dirigir el concierto social, nos invita a un gran congreso feminista que ha organizado, y en el que ofrece grandes premios a la muje que demuestre que la muer es un ser infinitamente superior. ¿Qué es el hombre? ¿Nuestro tirano? ¡Pues abajo el hombre!...Vamos a ver descreído// ives lo que yo te decía?/; Las mujeres de hoy en día/ ¡saben mucho!/ iConvenido!/ Saben mucho, es natural/ porque en cuestión de saber/ la ciencia de la mujer/ solo es la ciencia del mal... (Celso, Álvarez y Palomero, 1904: 8-9 y 36).

13 “Defendiendo los derechos/y el honor de la mujer,/ que los hombres atropellan/ sin cumplir con su deber./ Este trust hemos formado/ con la sola condición/ de humillar al sexo feo/ cuando llega la ocasión./ Ser libres queremos,/ tener voz y voto/ luchar en las Cortes,/ llevar los negocios./ Queremos carreras,/ cargos oficiales,/ industrias y oficio,/ empleos y gajes./ Queremos que el hombre caiga a nuestros pies/y triunfe la idea del mundo al revés./ Para conseguir el triunfo/ esta liga se formó,/ una liga que a los hombres/ se la voy a enseñar yo./ El emblema de esta liga/ es sencillo de verdad/ iAbajo los pantalones/y viva la libertad! (Montijano, 2009:714).

14 Yo vengo al Congreso/ dispuesta a hacer pupa,/ pues soy cabalina/ y de las de aúpa./ No hay un diputado/ que se me resista/ y todos exclaman/ ¡Vaya socialista!/ ... Diputada feminista soy/ y cobro mil pesetas saneás/ aunque al Congreso casi nunca voy/ lo mismo que hacen las demás/ ¡Diputada!/ Toos me dicen diputada di/Si es que arma bronca tu interpelación,/ y les contesto que al estar yo alli/ sé tié que armar en la sesión" (Montijano, 2009: 748). y transgresoras ${ }^{15}$.

En este ambiente hostil a las manifestaciones eróticas, a la exhibición del cuerpo y su sexualidad, a la castración de ideas, deseos y cualquier afirmación contraria a los cánones ultracatólicos impuestos, la revista tomará otros derroteros, será medio para impulsar ideología, aunque no pudiera evitar, en algunos momentos, llevar a escena, muy a su pesar, novedades y avances imparables.

La censura eliminó el destape, el "mal gusto", las expresiones soeces, etc. A partir de entonces, los maridos pudieron llevar a sus esposas a los espectáculos de revista y ellas sentirse cómodas en los teatros donde dichas funciones se exhibían, con independencia de los mensajes que desde la escena se les dirigiera, mensajes acordes con el pensamiento establecido, que pocas tenían posibilidad de cuestionar.

A juicio de Montijano, en la etapa franquista las mujeres pasan a ser las protagonistas de las obras y en torno a ellas gira todo el espectáculo, a diferencia de lo que sucede con las comedias musicales norteamericanas donde los hombres también pueden ser protagonistas. Afirma que "la mujer ha dejado de ser objeto para ser el elemento clave de toda la comedia musical". (Montijano, 2009: 116). Si bien esto es cierto, el problema es que resulta un sujeto de segunda categoría, incardinado en el marco teórico en el que se desenvuelve. De ahí, que en el ejemplo que el autor recoge perteneciente a la obra La Estrella de Egipto, en el diálogo, ante las libertades sexuales masculinas evidentes, la protagonista defienda que su madre le enseñó que "una mujer no puede dar un beso a un hombre, así como así... Debe ser siempre lo más personal..., lo más delicado que hay en nosotras...". Cuando a continuación canta dice: "a ninguna le interesa besar con frivolidad", con expresa referencia a la represión que había de ejercer la madre sobre la hija para educarla y esta sobre sí misma para no ser tomada como una mujer cualquiera, digna opositora al rechazo social y a su perdición. En cuanto al segundo ejemplo que toma de la obra Si Fausto fuera Faustina, las alusiones a la incapacidad femenina son explícitas en boca del protagonista: "no hay negocio que no salga al revés, si su opinión da una mujer".

15 Durante mi infancia, como sucederá con muchas otras personas de mi generación a nada que hagan memoria, fui testigo de tres situaciones diferentes de las que tuvieron lugar en los diferentes pisos de la casa donde yo vivía. Sin citar nombres, puedo decir que era vox populi que un significado varón del Régimen, vivía allí, en la zona noble, con su esposa y descendencia por el día, y por la noche dormía en su segundo domicilio donde le esperaba otra mujer y otros hijos. Nadie le criticó nunca abiertamente delante de mí y el respeto que se le debía era general. No sucedía lo mismo con las mujeres "perdidas" de la escalera interior, con historias y circunstancias absolutamente diferentes. Dos de ellas ejercieron durante un tiempo la prostitución, hasta que se convirtieron en las amantes respectivas de dos señalados individuos. La crítica era general y mordaz, ninguna mujer "de bien" se permitía detenerse con ellas en las escaleras y mucho menos en la calle, las miradas que les lanzaban los hombres eran descaradas, provocadoras, despectivas... Nunca llegaron a formalizar sus relaciones. 
Con la muerte del dictador y la llegada de la etapa histórica conocida como Transición, la revista pervivió unos cuantos años, aunque fue perdiendo relevancia pues había iniciado poco antes su decadencia. La necesidad de liberar todos los prejuicios, todos los condicionamientos, todas las prohibiciones, volvieron a llevar a escena el cuerpo desnudo de las mujeres para solaz masculino. No era el único medio: cine, prensa, televisión, publicidad... hacían uso de él, de nuevo, presentándolo como algo revolucionario, forma de expresar la ruptura con el período anterior y sus mensajes.

\section{Celia GÁMEZ: UNA VERSÁtIL diva ESCÉNICA}

Celia Gámez fue una diva escénica durante muchísimos años, más de cuarenta, porque supo nadar en todas las aguas, gracias a una versatilidad innegable y única.

Nacida en 1905, había iniciado su carrera en Buenos Aires, su ciudad natal, a la temprana edad de catorce años. Una serie de circunstancias ajenas a sus expectativas, pero que ella supo aprovechar, le permitieron debutar en Madrid, en el teatro Pavón. Fue el día de Navidad de 1925, en una gala benéfica a la que asistía lo más granado de la sociedad, con Alfonso XIII a la cabeza. Su éxito fue clamoroso y ya no se apagaría hasta pocos años antes de morir, nuevamente en Buenos Aires, en 1992.

Desde aquel día triunfal su prestigio fue creciendo hasta convertirse en la reina del escenario de la revista tal y como llegó a configurarse con el tiempo. Un tiempo que marcó las pautas de sus apariciones en escena y que como ya he indicado estuvo mediatizado por las sucesivas escenas políticas.

Sus primeros pasos los dio pues durante el reinado de Alfonso XIII, que la admiraba decididamente, le hizo regalos ${ }^{16}$, asistía con asiduidad a sus representaciones y le facilitó la nacionalidad española. Todo ello dio lugar a numerosas hablillas en torno a

un supuesto romance ${ }^{17}$, siempre negado por ella (García, 2010: 15).

La República la vio consolidarse y conquistar, como en la etapa anterior, a su principal representante, Manuel Azaña ${ }^{18}$.

Tras el paréntesis de la Guerra Civil, en la que Celia participó en el frente sublevado para entretenimiento de los soldados (Berges, 1967: 1162), llegaría su éxito rotundo. El clamor popular la mantuvo en escena hasta que sus años la obligaron a abandonar

16 "El día del estreno de Las Corsarias, Celia recibió en su camerino, entre otros regalos, una joya que le enviaba el monarca" (Montijano, 2009: 1120).

17 “Siempre se especuló sobre él y han sido muchos los testimonios que así lo aseveran. Pero, de igual modo, y como la figura mediática en que se convirtió, se le achacaron muchísimos otros amoríos que ella ni negaba, ni confirmaba, dejando crecer el mito" (García, 2010: 32)

18 Manuel Azaña estuvo presente en el estreno de Las Leandras y guardó para siempre en su cartera un nardo, del que nunca llegó a separarse, regalado por Celia Gámez" (Montijano, 2009: 410). como cabeza de cartel, en 1966, participando posteriormente en algunas obras teatrales hasta su retirada definitiva en 1984.

En estas sucesivas etapas históricas, Celia Gámez hubo de plegarse a las exigencias, estrategias y condicionantes impuestos por el gusto de los espectadores, la moral imperante y, por supuesto, las estrategias de los directores de escena y empresarios de los diferentes teatros ${ }^{19}$.

De ahí que en la primera y segunda etapa, en que se aplaudía la sicalipsis, ella participara en las obras insertas en tal contexto, que no le era ajeno pues se había iniciado en Buenos Aires, en 1919, en Las Corsarias, revista subida de tono y con un argumento plagado de enredos, chistes y dobles sentidos, en el que las mujeres raptaban a los hombres y se los rifaban; situación con la que, como no podía ser de otra manera, los hombres estaban encantados pues ellas no mostraban ningún recato y buscaban el amor de los rifados. El tratamiento que se da a las mujeres y la opinión sobre ellas aparece desde el principio del libreto ${ }^{20}$.

Ya en España, tras sus primeros pasos con canciones típicas argentinas, especialmente tangos, Celia Gámez se decantó decididamente por la revista. Paso a paso, con cada una de sus interpretaciones, irá ganando fama, con independencia de las características nada sobresalientes de su voz, con respecto a otras vedettes que sí se distinguían por ello. Su manejo de la escena era absoluto y con él rendía a su público ${ }^{21}$. 19 “Celia Gámez no salió nunca desnuda a un escenario, ni posó de tal guisa para los fotógrafos, con la exhibición de su bien formado cuerpo del que hacín un verdadero escaparate" (Femé, formado cuerpo del que hacian un verdadero escaparate" (Femenía, 20 “Voy a hablaros del mundo. Habéis de saber que estamos amenazados de grandes peligros. Y no es que nos persigan los lerrouxistas, anarquistas, socialistas, bolcheviquistas y sindicalistas. No es por ahí, hermanos; no es por ahí. Quien nos persiguen son las Evaristas. Digo Evaristas porque así llamo yo a las mujeres que son hijas de Eva. Ellas, que acabarán con el mundo entero, habiendo empezado por una manzana. Ya sé que no es moral que dentro del claustro tengamos que hablar de las faldas, pero es que se están organizando de tal manera, que el día que acaben de levantarse, nos hemos caído. Es más; un miembro de esta comunidad se ha caído por las faldas. Me refiero al padre Canuto... Os voy a leer una noticia publicada en The Times el día 7 del actual... Hace algún tiempo viene notándose la desaparición misteriosa de hombres que nunca pasan de los cincuenta años. E detalle curioso es que todos son solteros, y en su mayoría frailes y seminaristas... Corren rumores que se trata de un sindicato feminista establecido en varias islas de Oceanía, el cual se dedica a caza los hombres libres para hacerlos prisioneros del matrimonio. Se calculan en cien millones las solteras afiliadas al sindicato. Los policías de todos los países hacen gestiones para averiguar la certeza de la noticia y tomar las medidas necesarias" (Paradas y Jiménez, 1920: 2).

21 "Celia Gámez supo dar vida a todos estos números, imprimiéndoles su enorme personalidad que suplía airosamente la carencia de voz, que no era nada brillante y, sobre todo, su paupérrima tesitura que, con el paso de los años, fue reduciéndose hasta alcanzar unos límites que hacían que fuera casi un milagro poder componer música para ella, pues el compositor tuvo que moverse dentro de una octava... Pero el indudable arte de Celia Gámez hacía una creación de cada número, que nunca pudo ser igualada por otras artistas, aunque estas cantasen con más facultades de voz..." (Femenía, 1997: $322)$.

evista Internacional de Culturas y Literaturas, octubre 2016

ISSN: 1885-3625 
Hasta el estallido de la Guerra Civil fue adueñándose del escenario hasta convertirse en una de las vedettes más codiciadas, máxime cuando ella misma se convirtió en empresaria de su propia compañía.

En 1927, intervendrá en Las Castigadoras y Las burladoras del amor. Al año siguiente en Las lloronas y Roxana la cortesana. En 1929, lo hará en ¡Por si las moscas!, El antojo, El ceñidor de Diana y La martingala. Las cariñosas, La bomba, y Las guapas, se estrenarán en 1930. En 1931, Me acuesto a las ocho y Las Leandras. Los laureanos en 1932. Las tentaciones y Las de Villadiego se representaron en 1933. El baile del Savoy, La ronda de las brujas y Las inseparables, en 1934. Las siete en punto y Peppina en 1935.

Las Castigadoras no solo va a conferir fama a Celia Gámez, sino que dispensará a la revista una nueva estructura (Montijano, 2009: 372). La obra estará preñada de situaciones equivocas y de un omnipresente doble sentido en el lenguaje que hará del espectador parte esencial del juego teatral. Destacable será el chotis de Las taquimecas que con un sonido de fondo de máquina de escribir, evidenciaba la nueva profesión a la que las mujeres se iban incorporando, junto a las novedades en el vestir y el arreglo personal ${ }^{22}$. Pero serán los ojos de los varones y la exhibición femenina lo que más atraiga, según reza la crítica del estreno ${ }^{23}$. Además, del mismo modo que se daba carta de naturaleza a esta profesión, que llegará a ser casi exclusivamente femenina, se advertirá sobre los riesgos de otras inclinaciones, como acaece en ¡Por si las moscas!, en que se recomienda a Manuela, interpretada por Celia Gámez, que “deje de soñar y se dedique al oficio de su abuela, a planchar", o en Las Cariñosas, que en el chotis de La Lola, que la artista hizo más que célebre, se daba carta de naturaleza a las murmuraciones en torno a las mujeres que no guardaban debidamente las apariencias.

Pero si hay una obra con la que Celia Gámez conquistó definitivamente la escena fue con la revista Las Leandras, estrenada en 1931 y que se estrenó de nuevo en época de la dictadura bajo el título Mami llévame al colegio, con las obvias modificaciones impuestas por la censura, como la supresión del nombre de Victoria Kent, que se citaba en el chotis de El Pichi, mujer triunfadora, independiente y luchadora, convertida en abanderada de los derechos de las mujeres, espejo en fin en el que no debían verse reflejadas las españolas de postguerra.

22 "Con la falda muy cortita, muy cortita, ajustadita, luciendo el talle y el pelito muy cortito, muy cortito, yo, muy airosa, voy por la calle. Los zapatos muy chiquitos, muy chiquitos; las medias finas lo Rebeca, las muchachas taquimecas, mecas, mecas, son la admiración de los chicos cañón..." (Montijano, 2009: 379)

23 “Lo mejor de la revista estrenada anoche en Eslava fue la personificación de Las castigadoras. Cuando estas son de la calidad de Celia Gámez, la artista argentina de tan múltiples gracias, realzadas por su maravillosa escultura, no hay más remedio que entregarse, y apenas si queda tiempo para otra cosa que admirar sus encantos. Celia Gámez con su bella corte de muchachas... constituyó e mayor atractivo" (Montijano, 2009: 382).
Es en esa obra, precisamente, y en su cantable más famoso, el chotis de El Pichi, donde se da carta de naturaleza a una situación absolutamente degradante: la del hombre que maltrata a las mujeres y vive de ellas, gloriándose de sus estrategias y su "carisma" ${ }^{24}$. El hecho de que la interpretación fuese llevada a cabo por Celia Gámez, vestida de varón y su forma insinuante con respecto a las coristas, dio pábulo a comentarios que han llegado hasta nuestros días relativos a su inclinación homosexual.

Con todo, el público la adoraba y los críticos lanzaban continuados elogios de su buen hacer tanto en la preparación y composición del escenario y el lujo del vestuario como en su particular donaire en el cantar y moverse por el mismo, tal y como señala el ABC con motivo de estreno, en 1935, de Las siete en punto.

Todo lo que ella hiciera se ponía de moda y los más mínimos detalles de su vida cotidiana eran motivo de comentario, portadas y fotos en periódicos, semanarios revistas del corazón (García, 2010: 28). Celia regentaba en su vida privada un mundo femenino -formado por su madre y hermanas- donde ella mantenía la autoridad, merced a su prestigio social y poder económico. Durante mucho tiempo será utilizada como imagen de consumo: "una auténtica monomanía nacional que prácticamente la acompañó durante su larga vida artística" (García, 2010: 29).

Novedad propiciada por ella, con motivo del estreno de El baile del Savoy, fue la introducción del galán, como contrapunto a la vedette principal (Montijano, 2009: 62).

También contrataría, y aparecerían por primera vez en los espectáculos musicales españoles, a un grupo de bailarines, precisamente para esta revista, a quienes se llamó boys (Montijano, 2009: 867). En esta representación consiguió que las mujeres se sentaran en el patio de butacas, abandonando la idea de que quienes lo hacían eran de dudosa moral (García, 2010: 42).

24 "...pero yo que me administro, /cuando alguna se me cuela,/ como no suelte la tela,/ dos morrás la suministro;/ que atizándolas candela/ yo soy un flagelador.../ No reparo en sacrificios:/ las educo y estructuro/ y las saco luego un duro/ pa gastármelo en mis vicios,/ y quedar como un señor..." A y estructuro/ y las saco luego un duro/ pa gastarmelo en mis vicios,/ y quedar como un señor...". A pesar del contenido aquiescente con la violencia sobre las mujeres, su aceptación y popularidad han destinado a profesores de secundaria (Jurado y Rifón, 2005: 219). De hecho, como afirma Montijano "El éxito alcanzado por este ficticio personaje motivó a los autores a realizar otro chotis sobre la mujer de aquel simpático chulo madrileño bajo el título de la mujer del Pichi y que fue incluido en aquellos finales de fiesta en los que Celia Gámez, inmortal creadora de un inolvidable Pichi, tomaba parte" (Montijano, 2009: 244). En él se redondea el mensaje: las mujeres han de ser fieles, por muy engañadas que sean por sus parejas, no podrán permitirse hacer como ellos por miedo al repudio, e incluso a dejarle en mal lugar. Únicamente les queda el lamento, el llanto y los celos. El marido se configura como la única posesión posible de una mujer y sin él no puede vivir. Deberán estar rendidas a sus pies y competir por él con todas las armas a su alcance: Yo, señores, soy la Nati, la señora de ese Pichi tan nombrao.../ Desde la niña gilí/ a la señora jamón,// no hay en Madrid una socia/ que no esté mochales/ por ese ladrón./...y hace lo menos tres meses/ que el muy sinvergüenza/ ni un beso me ha dao./... Y yo nunca/ ni siquiera cuando sueño/ le he faltao/ pa que no haga mal papel/y que luego me repudie por infiel./ $\mathrm{Y}$ a eso no hay derecho/ porque mientras tanto/ los celos me matan/ y me ciega el llanto (Villora, 2007: 84-85). 
Una vez que estalló la Guerra Civil Celia Gámez permaneció en la zona ocupada por los sublevados hasta que pudo marchar a Buenos Aires, en 1937. Sin embargo, aunque fue contratada para realizar en su país algunas representaciones, nunca logró el éxito alcanzado en España. Decidió pues regresar, y lo hizo a finales de 1938. Recibió entonces la propuesta de cantar el chotis Ya hemos Pasao. Sería la respuesta al No pasarán que gritó Dolores Ibarruri en uno de sus discursos y que se convirtió en el lema republicano ante los sublevados.

De ahí que aunque en las entrevistas que se le realizaron con posterioridad, al igual que en sus memorias, se declarase apolítica, los hechos y vivencias demuestran lo contrario. Su connivencia con el régimen no se encuentra solo en aquella letra en la que se declara facciosa y llama miserables a los vencidos ${ }^{25}$, sino que puede observarse en sus relaciones con personas como Millán Astray, que fue su padrino de boda, el propio dictador, que la recibió en El Pardo, y su esposa, que la ayudó económicamente en momentos difíciles de su vida.

La dictadura será la etapa de triunfo indiscutible de una mujer admirada y alabada por todos. No tendrá problemas con la censura pues respetará las normas en cuanto a libretos y vestuario. Además supo "atraer a un público al que ella consideró idóneo para su teatro y su bolsillo" (Femenía, 1997: 318). Sin embargo no dejará de estar en boca de mucha gente por la irregularidad de su vida íntima en la que hubo matrimonio, separación y romances sucesivos que no se ajustaban al motor ideológico e inquisitorial impuesto en el país.

Año tras año, desde su aparición con El baile del Savoy, se sucedieron los estrenos, y año tras año permaneció en la cumbre, admirada, querida, aplaudida, mimada... Recibía la atención de hombres y mujeres de las clases medias y altas que veían que era un símbolo de estatus acudir al teatro, cuando la mayoría de la gente se encontraba acuciada por las necesidades más perentorias.

Cuando estrena La cenicienta del Palace, desaparece definitivamente de este tipo de obras la denominación "revista", porque la censura lo había prohibido. Desde entonces pasarán a llamarse comedias musicales (Montijano, 2009: 469).

25 “iNo pasarán! gritaban por las calles./ ¡No pasarán!// se oía a todas horas/ por plazas y plazuelas/ con voz de miserables./ ¡Ya hemos pasao!/ ya estamos en la Cava/ ¡Ya hemos pasao!/ con alma corazón/ ¡ Ya hemos pasao!/ y estamos esperando a ver caer la bola de la gobernación./ ¡Ya hemos pasao!/ Este Madrid es hoy de Yugo y Flechas,/ es sonriente, alegre y juvenil./ Este Madrid es hoy brazos en alto,/ que signos de paz lleva en el nuevo abril./ Este Madrid es hoy de la Falange,/ siempre garboso, alegre y lleno de su fe./ A este Madrid que cree en la Paloma,/ hoy que ya es libre, así le cantaré/ ¡Ya hemos pasao!,/ decimos los facciosos/iYa hemos pasao!/ gritamos los rebeldes..." (Montijano, 2009: 1129-1130).
Yola, en 1941, se convierte en fabuloso éxito revalidado por la crítica sobre Celia ${ }^{26}$, y sobre la obra de la que se indica se incardinaba en "una nueva etapa, más moderna, más limpia, mejor" (Montijano, 2009: 480). Se buscaba correr un velo ante el desastre de la guerra que había asolado España, como si vestir de plumas y lentejuelas y hablar de amor más o menos cándidamente, de ese amor que habían de buscar las mujeres sin más horizonte, pudiera borrar sus estragos: el horror de la muerte, el exilio, la depauperación, la represión feroz contra los vencidos. De ahí que las palabras de Celia retumbaran con mucho dolor en demasiados oídos: "todo era ingenuo, limpio, bonito, elegante, divertido... ¿Qué más podía pedir el público? Mis operetas, ya lo he dicho, invitaban a soñar" (Montijano, 2010: 478)

En Si Fausto fuera Faustina, de1942, Celia Gámez introducirá en su polifacética vida una actividad más, la de directora, de la que igualmente saldrá airosa. Como ya indiqué, en el libreto, como sucede en prácticamente todas las obras de la época se derrocha la imaginación para situar como bien absoluto el amor romántico. Igualmente, no se desperdicia la ocasión para hablar de la maldad intrínseca femenina: "Ya desde el pobre Adán todo se empezó a torcer, cuando surgió de pronto el modelo standar de mujer", y aludir a la imperiosa necesidad de las mujeres de "echar el lazo a un hombre", para resolver su porvenir, única meta a la que se le empujaba desde el momento mismo de nacer: "Que en el tren del matrimonio son escasos los asientos; todo es bueno y todo vale, con tal de coger un puesto". De ahí que su única preocupación será la belleza: "ser la más elegante, bella, rica, codiciada y hermosa de las mujeres terrenales", para sobresalir entre todas. Esa lucha se mostrará, como siempre por el patriarcado, como un enfrentamiento entre las mujeres: "Todos los hombres se rinden a los hechizos de Faustina, provocando las iras constantes del género femenino". (Heredia y Ochando,

1942).

En 1944, estrena Fin de semana, tras una serie de tristes avatares personales. No obtuvo el triunfo deseado, quizás preocupada por su proyectado matrimonio que tendrá lugar ese mismo año. La fama de Celia era de tal magnitud que la ceremonia se convirtió en un verdadero circo y escándalo para muchas personas.

En la cartelera permanecerá prácticamente un año su siguiente obra: Hoy como ayer. En 1945 se estrena Gran Revista, donde vuelve a ponerse ropa masculina y, nuevamente, su forma de actuar conquistando a las coristas destapó el murmullo de su lesbianismo (García, 2010: 79).

26 “ ¡Ay, Celia cada día mejor! Llenando por sí sola el escenario, y el teatro y el barrio. Y vestida de ta modo que las señoras prorrumpian en susurros, a cada salida, moviéndose con gracia y distinción cantando con ese buen gusto que da al género calidades singulares y bailando y haciendo con su personalidad indiscutible..." (Montijano, 2009:490). 
En 1946 lleva a escena Vacaciones forzosas, que no tuvo el éxito esperado. Sí lo conseguirá, al año siguiente, con La estrella de Egipto "que alcanzó récords de taquilla nunca vistos" (Femenía, 1997, 324). Una de las canciones, El beso, la convirtió en la cantante más famosa de España. El beso, como ya indiqué, y como tantas otras canciones y consejos que destilan sus obras, iba encaminada a fijar en el inconsciente femenino una peculiar forma de vivir, actuar, y lo que debía ser su máxima aspiración: encontrar el amor de su vida, sin el que no podría vivir. Así como los límites que debía marcarse, so pena de ser arrojada del esquema de lo considerado "decente".

En 1950 estrena Las siete llaves y La hechicera en palacio. Dólares ve la luz en 1954, pero no tiene éxito. Seguirá un largo paréntesis hasta que El águila de fuego, en 1956, le otorgue un éxito extraordinario. La obra se mantendrá en cartel durante tres temporadas. En los diferentes registros de la misma vuelven a aparecer fórmulas y recomendaciones dirigidas a las mujeres, dentro de la tónica del momento. Tal sucede con la letra de una de las canciones, la vespa, en la que se les ofrece algo absolutamente novedoso, pero que debería servir para que hicieran lo que estaba previsto para ellas: conseguir marido $^{27}$.

En 1958 la compañía de Celia Gámez pondrá en escena Su excelencia la embajadora, que permanecerá hasta los años 60, en que con La estrella trae cola, realizará una antología de los mejores números de sus anteriores representaciones.

1961 llevará a escena Colombina, y en el 65, ¡Aquí, la verdad desnuda! El tiempo ya le pasaba factura y después de la obra, estrenada en 1966, A las diez en la cama estés, desaparecerá como cabeza de cartel. No abandonará la escena y realizará aún algunos papeles de comedia como en La miniviuda al año siguiente, obra que no recibió buena acogida de la crítica ${ }^{28}$. Sus últimas interpretaciones las realizaría en Es mejor en otoño, en 1968, y en Los últimos de Filipinas, estrenada en 1972 donde la admiración que su fiel público le manifestó quedó recogida en la favorable crítica que se le dedicó ${ }^{29}$. Aún hará algunas apariciones en la televisión y en el cine, donde ya había incursionado

27 "...Toda mujer que es soltera/ en vespa debe montar/ y en la primera carrera/ a un hombre debe pescar..." (Montijano, 2009: 1594).

28 “El abnegado público que aún sigue yendo al teatro, especialmente, y por razones obvias, la noche del estreno se rió mucho y aplaudió frecuentemente durante la representación de la farsa de Juan José Alonso Millán: “La miniviuda”, de la que la famosa estrella de revista Celia Gámez se ha servido para iniciar una nueva carrera artística como actriz de comedia. El abnegado público que aún sigue yendo al teatro, a pesar de que muchas veces se le toma por subdesarrollado mental... Así es como se hacían antes os libretos de revista, y eso es lo que en el fondo le ha salido..." (ABC, domingo $10 \mathrm{de}$ septiembre de 1967).

29 “Celia Gámez, esplendorosa de arte y de belleza, entusiasmó a los espectadores con la exquisita y señorial picardia que pone en el escenario, en la pasarela y en el patio de butacas, pues a él bajó para cantar un delicioso número titulado "Deme usted la mano", cogiendo las de unos caballeros Celia, ídolo permanente de los públicos españoles, es una mujer de talento, una artista fabulosa, única en la tiempo atrás ${ }^{30}$ La última vez que pisará la escena será 1984. Ocho años después fallecía en Buenos Aires, perdida en sí misma por culpa de la terrible enfermedad del olvido.

\section{CONCLUSIONES}

De Celia Gámez se ha hablado mucho, como sucede con los personajes que descuellan por algo en un momento dado. Se dijo que ni tenía voz, ni tampoco una belleza espectacular. Tuvo, y sigue teniendo, sus partidarios incondicionales que defendieron a ultranza su savoir faire, como empresaria y como artista, exigente con los más mínimos detalles y puntillosa hasta el extremo. También sus más acérrimos detractores, principalmente entre los derrotados tras la Guerra, por el enaltecimiento de las consignas franquistas que asumió como suyas.

Su vida estuvo sujeta, como ha ocurrido siempre con la de la mayoría de las artistas, a los prejuicios patriarcales, dado que la propia idiosincrasia del oficio las proyecta con un vivir libre de ataduras, moviéndose de forma independiente, sin dueño que legítimamente establecido pueda controlar sus actos, siempre en el punto de mira.

Las mujeres dedicadas a los espectáculos de revista, considerados frívolos en su esencia, lo serían en mayor medida. Mostrarse libres sexualmente, capaces intelectualmente o en las labores emprendidas, e independientes económicamente, condiciones alabadas secularmente en los varones, siempre ha tenido un coste elevadísimo para las mujeres.

Sobre ella se tejieron historias sin cuento, relativas a su vida íntima, a sus relaciones amorosas, a sus tendencias homosexuales... Informaciones que han llegado hasta nosotros y que ahora poco importan, salvo para situarla en el marco de una época con un proyecto socio-político represor con la realidad y con la apariencia. De ah que esa libertad, si la hubo, hubiese sido transgresora, atrevida, desinhibida... y el régimen entornó los ojos porque le debía mucho. Le debía las canciones de triunfo y enaltecimiento patrio que, tras ser cantadas por ella, se extendieron a las bocas de millones de españoles y españolas. Le debía la puesta en escena machaconamente de modelos de hombres y de mujeres como "debían ser" ${ }^{\prime 31}$, enfrascados en sus pequeños o

revista y la comedia musical. Las calurosas ovaciones recibidas a lo lardo de su actuación en la noche del viernes testimoniaron una vez más, la admiración y el cariño que todos la profesan. Alcanzò uno de los mayores triunfos de su rutilante y casi legendaria carrera artística" (ABC, domingo 6 de febrero de 1972.

30 Las películas en las que participó a lo largo de su vida fueron: 1937 Murió el sargento Laprida 1938 EL diablo con faldas, 1940 Rápteme usted, 1969 Las Leandras, 1971 Canciones para después de una guerra, $1974 \mathrm{Mi}$ hijo no es lo que parece y $1981 \mathrm{El}$ bromista.

31 “La mujer así, ya con la entrada de los años cuarenta, acude a los teatros de revista para presenciar las deliciosas comedias musicales representadas por la artista bonaerense, soñando con encontrar un galán como el que la cortejaba, memorizando los deslumbrantes vestidos con que salía a escena y anhelando poder ser y sentirse tan deseada y arrolladora como ella" (Montijano, 2009: 278). 
grandes conflictos entre los sexos; modelos con los que las mujeres de la República y las mujeres comprometidas de siglos pasados habían intentado romper, mostrando que las mujeres no eran un cuerpo exhibible y enajenable, sino un intelecto en un cuerpo que merecía al menos tanto respeto como el de los varones que se habían erigido en sus dueños.

\section{REFERENCIAS BIBLIOGRÁFICAS}

Barce, R., "La revista. Aproximación a una definición formal”, Cuadernos de música Iberoamericana, 2-3 (1996-7), pp. 119-148.

Barreiro, J., "Los contextos del cuplé inicial, canción sicalipsis y modernidad”, Dossiers Feministes, 10 (2007), pp. 85-100.

Berges, C. (dir.), Enciclopedia biográfica de la mujer, vol. I, Barcelona, Garriga, 1967. Femenía Sánchez, R., La revista. Apuntes sobre la historia del género frívolo, Guadalajara, Geyser, 1997.

Fernández Soto, C., “La mirada hacia la mujer en la dramaturgia de Eugenio Sellés (1842-1926): madres, esposas, hijas, hijastras y ángeles de alas rotas", Stichomythia 8 (2009), pp. 108-126.

García Carretero, E., Celia Gámez, Memoria gráfica de la reina de la revista, Madrid, Ediciones Amberley, 2010.

Heredia Sáenz,J.L.y Vazquez Ochando, F., Si Fausto fuera Faustina. Comedia lirica en un prólogo y dos actos. <http://lazarzuela.webcindario.com/> (16.05.2016).

Labrador Ben, J. M. y Sánchez Álvarez-Insúa, A., Teatro frívolo y teatro selecto. La producción teatral de editorial Cisne, Barcelona (1935-1943), Madrid, CSIC, 2005.

Lucio, C., García Álvarez, E. y F. Palomero, M., Congreso feminista. Fantasía cómico lírica, Madrid, Sociedad de Autores Española, 1904.

Montijano Ruiz, J. J., "Panorama (breve y retrospectivo) de un teatro olvidado en España: La revista (1864-2010)”, UNED. Revista Signa, 20 (2011), pp. 447-470.

----, Historia del teatro olvidado: la revista (1864-2009).Universidad de Granada, 2009. Internet 20-05-16. <http://hera.ugr.es/tesisugr/18510413.pdf> (20.05.2016).

----, Madrid frívolo. Breve historia de la revista musical madrileña y los teatros que la albergaron, Madrid, La librería, 2013.

Paradas, E. y Jiménez, J., Las Corsarias. Humorada en un acto, colección La novela teatral, año V, no 108, Madrid, 1920.

Villora, P. M., (ed.),Teatro Frívolo, Madrid, Fundamentos, 2007. 